R. História, São Paulo. 120. p..3-25, jan/jul. 1989.

\title{
NOVAS INTERPRETAÇÕES DO TRÁFICO DE ESCRAVOS DO ATLÂNTICO
}

Herbert S. Klein*

RESUMO: Os estudos mais sistemáticos sobre o trafico de escravos possibilitaram inúmeras correições de conceitos ideológicos e de estimativas estatísticas inicialmente distorcidas pela campanha abolicionista. Confirmaram o predomínio do sexo masculino contra apenas um terço de mulheres e $10 \%$ de crianças. As próprias condições africanas definiram especificidades tais como o vulto demográfico e as porcentagens relativas de participação dos europeus. A multiplicação dos esforços de pesquisa levou a re-avaliações importantes sobre o papel do tráfico no crescimento econômico dos paises europeus, a distribuição das diversas culturas no continente americano e o seu efeito sobre a demografía e a economia africanas.

UNITERMOS: tráfico, escravidão, abolicionismo, historiografia.

O tráfico de escravos do Atlântico, apesar de sua importância central na história econômica e social do imperialismo ocidental, de seu papel fundamental na história da América e de seu profundo impacto sobre a sociedade africana, permaneceu como uma das áreas menos estudadas na moderna historiografia ocidental até as ultimas décadas deste século. O interesse tardio não se deu por falta de fontes, pois o material disponível para seu estudo foi abundante desde o começo. Ao contrário, foi ignorado devido a sua associação com o Imperialismo europeu de que resultou falta de interesse por um problema moralmente difícil, a que se acresceu a falta de instrumental metodológico, que permitisse analisar complexos dados quantitativos.

Os primeiros estudos do tráfico de escravos do Atlântico começaram na década de 1780 no auge de seu crescimento, quando cerca de 79.000 escravos por ano chegavam aos portos americanos. Buscando estruturar uma ar-

\footnotetext{
Departamento de História, Columbia University.
} 
KLEIN. Herbert S. Novas interpretações do tráfico de escravos no Atlântico

gumentação contrária à migração forçada de escravos africanos, abolicionistas ingleses procuraram determinar as dimensões básicas do Tráfico, os padrões de mortalidade dos escravos e da trípulação e o impacto econômico do tráfico sobre a economia africana e americana. Com a meta de prover uma propaganda eficaz para sua campanha, os abolicionistas ainda assim se engajaram em pesquisas sérias. Da mesma forma, quando o Parlamento inglês começou a impor suas primeiras restrições formais aos traficantes, nas décadas de 1780 e 1790, iniciou-se a primeira coleta sistemática de material estatístico sobre o tráfico pelas agências governamentais britânicas, um serviço ao qual o governo daria continuidade até meados do século XIX 1.

Alem destas fontes publicadas, quase todas as nações escravistas européias mantiveram detalhados registros estatísticos sobre o tráfico por motivo de imposto ${ }^{2}$. Um bom número de registros de companhias privadas acabaram por serem incluidas nos arquivos nacionais da Europa e da América no século XIX ${ }^{3}$. Finalmente, no final do século XVIII e início do XIX, jornais comerciais mantinham registros detalhados de embarque e desembar-

1 Muito deste material quantitativo permaneceu sem publicação até bem recentemente. A principal coletânea impressa até a década de 1960 era o arrolamento que o Foreign Office publicou sobre o tráfico de 1817 a 1843, que se encontra em Parliamentary Papers, 1845, XLIX (73), p. 593-633. Este conjunto de dados foi usado originalmente por Curtin em seu trabalho de 1969 citado abaixo, e foi atualizado por Klein corn base nos jornais do Rio de Janeiro e suas listagens de desembarque no porto para o período que vai até 1830 , ver KLEIN, Herbert S. . The Middle Passage, Comparative Studies in the Atlantic Slave Trade, Princeton, 1978, cap. 4. Esta lista foi aprovada e complementada com mais informações vindas do Public Record Office. Ver ELTIS, David. Economic Growth and the Ending of the Transatlantic Slave Trade. Nova Iorque, 1987.

2 Publicações recentes de novos materiais de arquivos incluem o estudo monumental do tráfico de escravos francés de Jean Mettas. Répertoire des expéditions négrières françaises au XVlIIe siècle. Paris, 1978-84. 2 vols.; e uma listagem mais completa para a Virginia por Walter Mindinton, et at., Virginia Slave Trade Statistics, 1698-1775. Richmond, Va., 1984.

3 Para a Companhia das Índias Ocidentais holandesa, ver ex. Johannes Postmann. The Dimensions of the Dutch Slave Trade from West Africa, Journal of African History, XIII, $\mathrm{n}^{\circ}$ 2, 1972; para as Companhias de monopólio brasileiras organizadas à época de Pombal, ver CARREIRA, Antonio. As Companhias Pombalinas de navegação, comércio e tráfico de escravos. Porto, 1969. Sobre as companhias inglesas e francesas, ver LY, Abdoulaye. La Compagnie du Sénegal, Paris, 1958; e DAVIES, K.G, The Royal African Company. Londres, 1951. 
que de navios negreiros africanos ${ }^{4}$ Com todas estas fontes publicadas e documentadas, algo em torno de um terço ou mais de todas as viagens de escravos realizadas deixaram registro escrito ${ }^{5}$

Contudo, depois da década de 1810, houve pouco interesse em analisar o tráfico. Os abolicionistas britânicos haviam convencido seu próprio governo a terminar com o comércio negreiro e assim procederam ao uso da forca e da coerção para abolir o tráfico de outras nações. Concomitantemente, o fim do comércio de escravos do Atlântico em meados do século XIX coincidiu com a conquista e colonização da África, bem como com o crescente domínio da ideologia imperialista e racista do pensamento metropolitano. Neste contexto havia pouco interesse em discutir o tráfico de escravos, considerado pela maioria dos escritores como, na pior das hipóteses, um mal necessário, quando não um beneficio ao mundo através de seus esforços tidos como "civilizadores".

Apenas com a crise da Primeira Guerra Mundial é que os intelectuais europeus começaram a questionar as premissas básicas subjacentes ao Imperialismo. Neste debate o tráfico de escravos do Atlântico tornou-se um dos "crimes" do imperialismo ocidental e passou a ser denegrido. Foi desta perspectiva paternalista que os escritores começaram a reestudar o contato europeu com resto do mundo. O resultado foi uma narrativa cheia de estórias de violência e exploração, baseadas num mínimo de pesquisa e na ignorância

4 Um exemplo disto é a coletânea de notificações de navios que se encontram nos jornais do porto do Rio de Janeiro, ver KLEIN, Herbert S. e ENGERMAN, Stanley L.. Shipping Pattern and Mortality in the African Slave Trade to Rio de Janeiro, 1825-1830, Cahiers d etudes africaines. v. 59, n. 15.1975.

5 De todas as rotas do tráfico, as que foram para a América Espanhola são as menos bem documentadas. Algum material estatístico pode ser encontrado nos seguintes trabalhos: STUDER, Elene F.S., La trata de negros en el Rio de ia Plata durante el siglo XVIII. Buenos Aires, 1958; PRECIADO, Jorge Palacios. La trata de negros por Cartagena de Indias. Tunja, Colombia, 1973; PALMER, Colin, Human Cargoes, the British Slave Trade to Spanish America, 1700-1739. Urbana. III., 1981; RAMIRES, Bibiano Torres. La Compañla gaditana de negros. Sevilha, 1983. Todos concentram-se no século XVIII. Para períodos anteriores ver V1LAR, Enriqueta Vila. Hispanoamérica y el comercio de esclavos. Los assientos portugueses. Sevilha, 1977 e FRANCO, Maria Vega. El tráfico de esclavos in América, 1674-Sevilha, 1984. 
KLEIN, Herbert S. Nova interpretações do tráfico de escravos no Atlântico.

de fontes arquivisticas. Esta literatura criou uma série de mitos sobre os custos do tráfico, os padrões de embarque dos escravos através do Atlântico, a mortalidade sofrida e os ganhos e benefícios gerais para os europeus. Sobrecarregamento dos barcos, "astronômicas" taxas de mortalidade de 50\% ou mats, "escravos baratos" comprados por contas supostamente sem valor e o assim chamado "tráfico triangular", tudo foi visto como crimes. Sugeriu-se que os lucros do tráfico teriam provido o capital crucial necessário para financiar a Revolução Industrial ${ }^{6}$.

Mas apesar do domínio desta literatura acrítica que ainda sobrevive em livros de história para cursos de nível secundário e universitário, estudos críticos começaram a aparecer na segunda década do século XX. Um dos primeiros estudos acadêmicos foi o trabalho de um pequeno grupo de estudiosos franceses e norte americanos. Gaston-Marün e Padre Rinchon na França e Elizabeth Donnan, nos Estados Unidos, foram os primeiros a iniciar um estudo sistemático do tráfico, reunindo muito do material disponível nos arquivos franceses e ingleses. Estes estudiosos publicaram uma série de estudos inovadores nas décadas de 1920 e $1930^{7}$. Estas coletâneas ao lado do impressionante levantamento inicial de Gaston-Martin, serviram de base para os estudos mais atuais do tráfico de escravos, no período posterior à segunda guerra mundial ${ }^{8}$.

Mas foi o crescimento do novo campo de História africana bem como o despertar do interesse pela História Afro-americana nos anos 50 e 60 deste século, que finalmente desencadearam o grande esforço nas pesquisas desta área. Apesar de que muitos estudiosos estivessem começando a trabalhar com vários aspectos do tráfico dentro da perspectiva africana, européia e americana, foi o trabalho de Philip Curtin o que provocou uma decisiva reorganização e reelaboração de toda a experiência. Em 1969 ele publicou seu The Atlantic Slave Trade: A Census ${ }^{9}$, em que se propunha calcular o

6 Ver, ex., MANNIX, D.P. e COWLEY, M. Black Cargoes: History of the Atlantíc Slave Trade, 1518-1865. Nova Iorque, 1962; e POPE, James - Hennesey Sins of the Fathers: A Study of the Atlantic Slave Traders, 1441-1807. Londres, 1967.

7 RINCHON, Dleudonné. La traite et Fesclavage des Congolais par Us europiens. Brussels, 1929; DONNAN, Elizabeth. Documents lllustratives of the History of the Slave Trade to America, Washington, D.C., 1930, 4 VOIB.; Gaston-Martín, Négriers et bois d ebene. Grenoble, 1934.

8 Gaston-Martin, Nantes au XVIIIe siécle. L'ère des négriers (1714-1774). Paris. 1931.

9 Publicada pela University of Wintconsln Press em Maditon. 
R. História, São Paulo, 12O,p.3-25, jan/jul. 1989.

volume do tráfico a partir das fontes secundárias disponíveis. Uma contribuição original para a metodologia histórica bem como para o campo de estudos de tráfico de escravos, o trabalho de Curtin fornecia uma estimativa do volume total do tráfico de escravos africanos para a Europa, as ilhas do Atlântico e a América, desde os anos de 1440 até 1860. O trabalho incluía um exame minucioso de todas as estimativas publicadas - a maioria das quais se revelaram atrozmente exageradas - e uma cuidadosa reconstrução das cifras por região e período baseada em modelos explicitamente demográficos e econômicos. Mesmo concentrando-se no tema do número de africanos embarcados, Curtin teve que pesquisar todos os assuntos que posteriormente se tornariam temas básicos nesta importante área de pesquisa. A evolução demográfica das populações escravas americanas foi a preocupação fundamental de Curtin, assim como a mortalidade sofrida ao se atravessar o Atlântico, uma vez que estes eram fatores primários que permitiam calcular o número de africanos transportados, quando nenhum outro dado em disponível. Ble também tocou em problemas do crescimento da população africana e do interesse econômico dos europeus, pelo tráfico.

Mas foi sua estimativa de um tota! de 8 a 11 milhões de africanos transportados durante todo o período do tráfico, que provocou a resposta mais imediata dos estudiosos. O debate resultante gerou uma busca maior em fontes não publicadas atrás de números e de novas fontes para desafiar ou apurar as cifras por ele obtidas. Foi esta busca internacional em arquivos europeus, americanos e africanos atrás de todos os dados existentes sobre as viagens dos navios negreiros, que abriu um novo $t$ importante período de pesquisas e análises do tráfico negreiro do Atlântico. Quando este novo material tomou-se disponível, muitos debates antigos puderam ser diretamente abordados e novas e mais sofisticadas questões puderam ser levantadas sobro a história econômica, social e até política da primeira grande migração humana transoceánica. Este novo conhecimento resultou num surpreendente volume de publicações internacionais, que tomaram este campo um dos mais ativos e produtivos da historiografia contemporânea ${ }^{10}$.

10 Algumas das conferências e volumes do coletânea de ensaios neste assunto induem: ENGERMAN, Stanley L.e GENOVESE, Eugene, eds.. Race and Slavery in the Western Hemisphere: Quantitative Studies, Princeton, 1975; JEREMY, Henry A. and HOGENDORN, Jan S.. The Uncommon Market: Essays on the Economic History of the Transatlantic Slave Trade, Nova Iorque, 1979; o volume especial dedicado ao tráfico da Revue française $d$ ' histoire $d$ Outre-Mer, v, 62, n. 226-227, 1975. Roger ANSTEY e P.E.H, HAIR, eds., Liverpool, the African Slave Trade and Abolition Liverpool, 1976; ELTIS, David e WALVIN, James, eda.. The Abolition of the Atlantic Slave Trade. Madlson, Wiso., 1981; SOLOW, Barbara L. e ENGERMAN, Stanley, eds.. British Capitalism and Caribbean Slavery. Cambridge, 1987; e a publicação futura doa trabalhos da Conferência internado nal de Nantes sobre o tráfico negreiro, de 19S5 a serem editado» por Serge Daget. 
KLEIN. Herbert S. Novas interpretação do tráfico de escravos no Atlântico.

As questões abordadas nestes recentes estudos podem ser agrupadas numa série de temas inter-relacionados, e são estas publicações e os debates gerados que eu gostaria de analisar neste ensaio. Estas questões se referem à economia básica do tráfico, seu impacto demográfico e finalmente as causas e conseqüências de sua abolição.

As questões sobre a economia do comércio de escravos começam pela mais fundamental de todas - , quem teria se beneficiado com o tráfico de escravos. Inicialmente achava-se, na literatura tradicional, que o tráfico era um monopólio europeu pelo qual os africanos recebiam pouca compensação. Argumentava-se que os lucros eram astronômicos uma vez que os escravos podiam ser comprados com produtos europeus sucatcados, de segunda mão ou de qualidade inferior, ou seja muito abaixo de seu real valor ".

Mas desde os primeiros estudos de Rinchon e Gaston-Martin até as detalhadas análises mais recentes das despesas com abastecimento ${ }^{12}$, é evidente que os escravos comprados na África não eram um artigo barato. $O$ valor dos bens exportados para a África de forma a pagar pelos escravos consistiam em custosos produtos manufaturados que eram o fator de equipamento mais caro da viagem, valendo mais que o próprio navio, que os salários da tripulação e que o abastecimento alimentar todos juntos. Por exemplo, dois terços dos custos do equipamento dos traficantes franceses do século XVIII, era composto de bens usados para a compra de escravos. ${ }^{13}$ Ainda mais, as exigências africanas demandavam os produtos exportados para a

11 De acordo com Williams, os lucros teriam sido astronômicos a ponto de terem financiado o surgimento da indústria inglesa. Nesta tese origina] e ainda significativa, Williams propunha uma conexão causal entre o tráfico negreiro, escravidão americana e a industrialização da Inglaterra. WILliAMS, Eric. Capitalism and Slavery. Chapel Hill, 1944.

12 RINCHON, Dieudonné. Les armaments négrièrs au XVIIe siècle. Bruxelas, 1956; MEYER, Jean. L'armement nantais dans la deuxième moitté du XV/IIe siècie*Paris, 1969; ANSTEY, Roger, The Atlantic Slave Trade and British Abolition, 1760-1810. Londres, 1975; STEIN, Robert Louis, The French Slave Trade in the Eighteenth Century: An Old Regime Business. Madison, 1979; COUGHTRY, Jay. The Notorious Triangle; Rhode Island and the African Slave Trade, 1700-1807. Philadelphia, 1981; CARRERA, Antonio. As Companhias Pombalinas. Porto, 1969.

13 Meyer, L'armement nantais, pp. 161-163. Duas fontes independentes (ver Klein, Middle Passage, p. 169) mostram que a carga mandada para a África nos navios no final do século representavam $65 \%$ do custo total. 
R. História, São Paulo, 120, p.3-25, jan/jul, 1989.

região do sub-Saara, em cuja lista finos tecidos das índias Orientais figuravam em primeiro lugar. Tão importantes e caros eram os tecidos asiáticos neste comércio que os europeus - especialmente os ingleses - tentaram desesperadamente substituí-los por imitações européias mais baratas, mas com pouco proveito. De fato Foi sua importância como portos no comércio asiático que fez com que Liverpool e Nantes enriquecessem tanto como os principais portos no tráfico negreiro da Inglaterra e da França respectivamente, no século XVIII.

Em seguida vinham, enquanto importância econômica, as barras de metal, instrumentos agrícolas, implementos domésticos, armas, pólvora, brandy, rum e outras bebidas alcoólicas, tabaco e muitos outros produtos relativamente caros. ${ }^{14}$ Mesmo quando os europeus usavam produtos africanos para comprar escravos estes, por sua vez, eram comprados com produtos manufaturados europeus ou asiáticos, Todos estes produtos eram comprados por traficantes em moeda forte. Mais ainda, ao contrário da maioria do comércio colonial europeu, o comércio africano requeria a compra de uma grande quantidade de material não nacional - tudo, desde tabaco brasileiro e mobília holandesa, até tecidos das índias Orientais.

Ao lado de mitos como o suposto baixo custo dos escravos, a literatura tradicional salientava a posição dependente dos comerciantes africanos no tráfico, Pensava-se que os preços cobrados pelos escravos eram baixos e constantes, que o tráfico tora dominado por europeus e que os africanos eram observadores passivos de todos os processos. Mas, ao contrário, todos os estudos demonstram que a mistura de bens que compunha o preço de cada região tendia a variar com o tempo e refletia a transformação das condições de oferta e procura. Assim, os comerciantes africanos ajustavam sua demanda de bens respondendo às condições do mercado.

Os africanos também foram astutos e persistentes ao evitar que os europeus criassem condições de formar um monopólio. Os poderosos europeus

14 Os traficantes estabelecidos na América tinham menos acesso aos tecidos da Ásia e aos produtos manufaturados europeus e tinham que se apoiar nos produtos americanos procurados na África - acima de tudo rum e tabaco - os dois produtos-chave transportados por traficantes norte americanos e brasileiros. Ver COUGHTRY, Jay. The Notorious Triangle, p. 80ss.; REBELO, Manoel dos Anjos da Silva, Relações entre Angola e Brasil, 1808-1805. Lisboa, 1970; e VERGER, Pierre. Flux et Reflux de (a traite de nègres entre le golfe de Benin et Bahia de Todos os Santos, du dix-septième au dix-neuvièrne siècle. Paris, 1968, 
KLEIN, Herberts. Novas interpretações Jo tráfico de escravos no Atlântico.

na África ocidental e até nas cidades portuguesas no litoral e no interior do sudoeste da África eram ineficazes para impedir que compradores rivais entrassem no mercado local. O domínio exercido pelos mais fortes tinha o alcance de apenas algumas milhas para o interior e eram mais apropriados para afastar competidores que para ameaçar abastecedores. Quanto aos exclusivos estabelecimentos portugueses, eles também foram incapazes de impedir os franceses e ingleses de obterem escravos congoleses e angolanos cm escala maciça. Entretanto, estes domínios eram tidos como totalmente monopolizados pelos portugueses.

Deve-se salientar que o tráfico era um negócio complexo englobando tantos pontos fixos, como fortes litorâneos ou portos, como também barcos que navegavam aleatoriamente $\mathrm{cm}$ águas costeiras. Os comerciantes africanos também variavam consideravelmente, de intermediários mulatos até monopólios estatais de comércio e organizações de comércio nobres ou reais. Alguns estados eram suficientemente fortes para impor pesadas tarifas ao tráfico, em outras regiões o comércio era livre. Mas em toda parte eram os africanos que controlavam o volume de escravos e determinavam os tipos a serem oferecidos. E eram eles que determinavam os preços.

Se o tráfico era rentável na micro-esfera do indivíduo, ou grupo, ou comércio de classe, permanescía ainda a questão de seus custos sociais. Os ataques repentinos de comerciantes de escravos contra agricultores e o subsequiente abandono de boas áreas cultivadas, a ênfase na defesa ou em atividades militares e o desvio de jovens adultos da força de trabalho, todos estes aspectos tiveram custos econômicos a longo prazo. Mas para aqueles engajados no tráfico e para a imensa maioria de africanos que consumiam produtos importados asiáticos e europeus, o comércio de escravos era uma atividade lucrativa quaisquer que fossem suas conseqüências para o desenvolvimento econômico a longo prazo.

A literatura tradicional considerava que o baixo custo dos escravos tornava rentável o acúmulo de maior número possível de escravos nos navios negreiros, desde que não se colocasse este líltimo em risco de afundar e, desta forma, contribuíam para as altas taxas de mortalidade durante a travessia do Atlântico. Se qualquer escravo que chegasse vivo era puro lucro, então a perda de vários centenas deles faria sentido econômico. Entretanto, se os escravos não fossem baratos o argumento do "sobrecarregamento" tam- 
R. História, São Paulo, 12O.p.3-25,jan/jul. 1989.

pouco faria sentido. Ao contrário, a alta taxa de mortalidade na travessia resultava em prejuízo total da viagem ${ }^{15}$.

Ainda mais convincentes que estes argumentos contra uma destruição inconseqüente de vidas, é o fato de nenhum estudo até agora ter demonstrado uma correlação sistemática significativa entre o número de escravos carregados e a mortalidade no mar. Milhares de travessias de navios já foram estatisticamente analisadas e nenhuma demonstra uma correlação significativa entre tonelagem ou espaço disponível e mortalidade ${ }^{16}$.

Isto não significa que os escravos viajavam com luxo. Contavam com menor espaço que tropas do exército ou grupos de condenados em trânsito. Significa, simplesmente que depois de muita experiência e em função das próprias exigências do comércio de escravos, os traficantes embarcavam somente tantos escravos quantos pudessem atravessar o oceano em segurança. A partir de referências esparsas do período anterior a 1700 parece que a organização de abastecimento e carregamento era inicialmente deficiente. Mas, todos os estudos do tráfico pós-1700 demonstram que os traficantes carregavam água e abastecimento para o dobro do tempo em que esperavam cumprir a viagem, e que na maioria dos casos carregavam um número ligeiramente inferior de escravos ao permitido por lei.

Esta crescente sofisticação em carregar os escravos refletiu-se na queda das taxas de mortalidade. Antes de 1700 a taxa média de mortalidade cobrindo muitas viagens pairava em tomo de $20 \%$. No entanto esta taxa média refletia amplas variações: alguns navios chegavam com taxas muito baixas, e um número igualmente alto com taxas de o dobro ou mais da média. Mas depois de 1770 ambas as taxas sofreram uma queda, e a variação em torno da média diminuiu. Já em meados deste século a média de perdas ficava em torno de cerca a $10 \%$ e, no último quartel deste, todo o tráfico tinha uma taxa média de 5\% de mortalidade, Além disso a variação em torno destas taxas médias havia caido e dois terços dos navios operavam com taxas de mortalidade iguais ou inferiores à média.

Esta queda na mortalidade devia-se à crescente padronização adotada no tráfico. Embarcações especiais foram construídas para o tráfico negreiro

15 STEIN, Robert calculou que "a morte de cada escravo numa expedição de 300 escravos, teoricamente reduzia os lucros em 67 por cento, o a taxa média de mortalidade de 10 a $15 \%$ reduzia os ganhos de 20 a 30 por cento." H. Stein. The French SlaveTrade. p. 141-142.

16 GARLAND, Charles e KLEIN, Herbert S.. The Allotment of Space for African Slavers Aboard Eighteenth Century British Slave Ships, William \& Mary Quarterly, v. 62,n. 2, 1985. 
KLEIN, Herbert S. Novas interpretações do tráfico de escravos no Atlântico.

de todas as nações. A partir da segunda metade do século XVIII, os navios negreiros pesavam uma média de 200 toneladas entre os vários traficantes europeus, tonelagem esta que parecia a mais adequada para um potencial de carregamento de êxito do tráfico. Os traficantes de escravos também foram os primeiros comerciantes a adotarem uma camada protetora de cobre em seus navios, um método custoso para prolongar a vida de suas embarcações e garantir maior velocidade. Deve-se salientar que as embarcações negreiras eram bem menores que as usadas pelos europeus tanto no comércio das índias ocidentais como orientais. Isto por sua vez avança bem a explicação de porque o famoso modelo do comércio triangular (produtos europeus para África, escravos para América e açúcar para a Europa, tudo na mesma viagem) é, em grande parte, um mito. A maioria da safra americana chegava ao mercado europeu em embarcações bem maiores especialmente construídas para esta frota comercial; a maioria dos traficantes negreiros voltava com pequenas cargas ou simplesmente nenhuma; e no maior tráfico negreiro de todos - o do Brasil - nenhum traficante embarcava ou retornava à Europa.

Todos os traficantes carregavam um escravo e meio por tonelada c, embora houvesse variação quanto ao tamanho e proporção das tripulações, todos os navios negreiros tinham tripulações de o dobro ou mais daquela necessária para operar a embarcação, conseqüentemente também, de o dobro ou mais de qualquer embarcação comercial transatlântica. Esta alta proporção de marinheiros por tonelagem devia-se à necessidades de segurança para se controlar os prisioneiros escravos. Todos os traficantes europeus também usavam o mesmo tipo de abastecimento, de procedimentos de saúde e transporte - construindo um convés temporário para suas moradias c dividindo-os por idade e sexo. Quase todos os europeus adotaram vacinação contra varíola mais ou menos ao mesmo tempo, todos carregavam grandes quantidades de abastecimento alimentar africano para os escravos, e todos usavam os mesmos métodos de higiene, exercício e cuidados com os doentes no dia a dia. Esta padronização explica a generalizada queda de mortalidade e reforça consideravelmente a rejeição de afirmações feitas por testemunhos contemporâneos de que certos comerciantes europeus seriam "melhores" que ou$\operatorname{tros}^{17}$.

17 Para uma detalhada discussão destas questões e para material sobre mortalidade, ver Klein, Middle Passage, caps. 4, 7 \& 8. Uma recente e controvertida volta à visão mais tradicional sobre a mortalidade de escravos na travessia, enfatizando as assim consideradas, perversas características dos comerciantes brasileiros - por oposição aos europeus - pode ser encontrada em Joseph Miller, The Way ofDeath: Merchant Capitalism and Angolan Slave Trade, 1730-1830. Madison, Wise, 1988. 
R. História, São Paulo, 120. p.3-25. jan/jul. 1989,

Embora estas estatísticas bem fundamentadas certamente destruíram muitos dos velhos temas sobre a mortalidade "astronômica" e "sobrecarregamento", permanece a questão de se $5 \%$ de mortalidade para viagens de trinta a cinqüenta dias de saudáveis jovens adultos é alta ou baixa. Se tal mortalidade houvesse ocorrido entre jovens camponeses na França do século XVIII teria sido considerada uma taxa epidêmica. Assim, embora os europeus tenham conseguido reduzir as taxas a porcentagens aparentemente baixas, estas ainda representavam índices de mortalidade extraordinariamente altas para uma população seleta de jovens saudáveis. Da mesma forma, enquanto as taxas de mortalidade de tropas, imigrantes e condenados no século XVIII se aproximava à dos escravos, já no século XIX elas caíram consideravelmente para menos de $1 \%$ em travessias transatlânticas. Quanto aos escravos, entretanto, a taxa nunca caiu para menos de $5 \% \mathrm{~cm}$ qualquer grande grupo de embarcações já estudados. Assim, parece ter havido, paradoxalmente, uma taxa mínima devida a um certo sobrecarregamento, que os europeus nunca conseguiram reduzir ${ }^{18}$.

As mortes nas travessias tinham várias causas. Os maiores agentes eram as desordens gastrointestinais, freqüentemente relacionadas com a qualidade de alimento c de água disponíveis na viagem. Surtos de desinteria eram comuns e a "bloody flux", como era chamada, as vezes irrompia $\mathrm{cm}$ proporções epidêmicas. A crescente vulnerabilidade dos escravos à desinteria aumentava tanto as taxas de contaminação dos estoques quanto as de morte. A desinteria era responsável pela maioria das mortes e era a doença mais comum em todas as viagens. As astronômicas taxas de mortalidade alcançadas $\mathrm{cm}$ algumas viagens deviam-se a surtos de varíola, sarampo e outras doenças altamente contagiosas, que não estavam relacionadas com o tempo de permanência no mar, nem com as condições de estoques de alimento e de água, e nem com a higiene ou as práticas sanitárias. Era a própria casualidade destas doenças epidêmicas que impedia capitães experientes e eficientes de eliminar as altas taxas de mortalidade de algumas viagens.

18 Isto pode explicar os achados recentes de 92 viagens selecionadas, dos anos de 1790, que demonstram uma correlação entre "sobrecarregamento" e mortalidade devido a doenças gastrointestinais. STECKEL, Richard H. e JENSEN, Richard A.. New Evidence on the Causes of Slave and Crew Mortality in the Atlantic Slave Trade, Journal of Economic History, v, 46, n. 1, 1986. 
KLEIN, Herbert S. Novas interpretações do tráfico de escravo» no Atlântico,

Embora o tempo de permanência no mar não fosse normalmente correlacionado com mortalidade, havia algumas rotas em que o tempo era mesmo um fator ponderável. Por serem um terço mais compridas que as outras rotas, o comércio da África oriental, que se desenvolveu em fins do século XVIII e início do XIX, chamava atenção para taxas de mortalidade de uma maneira geral maiores que as da África ocidental, apesar da mortalidade diária no mar ser mais baixa que a das rotas menores. Além disso, o carregamento de escravos de todo tipo de regiões epidemológicas da África, por si só já propiciava a transmissão de várias doenças endêmicas locais para todos que se encontravam a bordo. Por sua vez, isto garantiu a dispersão na América de todas as principais doenças africanas ${ }^{19}$.

Os estudos do tráfico comprovam uma constante predisposição contra mulheres e crianças. As mulheres representavam uma média de um terço a um quarto dos africanos forçados a migrarem, e as crianças representavam uma média de $10 \%$ ou menos. Apesar de haver flutuações ao longo do tempo e do espaço, de uma maneira geral estes números eram surpreendentemente constantes. Para muitos pesquisadores trata-se de fatores específicos da demanda americana e não de uma simples seleção casual. Este aspecto do tráfico vinha justapor-se à discussão contemporânea, um tanto extensa, na literatura dos séculos XVIII e XIX, sobre os defeitos e qualidades de diferentes grupos africanos quanto aos seus hábitos de trabalho, Mas assim como a percepção do domínio foi desafiada em termos da compra de escravos e de seu custo, os fatores da demanda americana como sendo a principal influência na determinação dos tipos de escravos transportados, também o foram.

É claro que a cronometragem da migração destes africanos e os lugares para onde eram entregues eram determinados em grande parte pelas condições americanas, Uma região qualquer americana, até mesmo quando fosse oferecido crédito para comprar escravos, não poderia entrar no comércio sem uma safra que pudesse ser comercializada na Europa. Da mesma forma a movimentação de escravos através do Atlântico era de natureza periódica devido às correntes e aos ventos principais que influenciavam a travessia e à

19 Ver, p. ex., KIPLE, Kenneth F. $c$ KING, Virginia H.. Another Dimension to the Black Diaspora: Diet, Disease and Racism. Cambridge, 1981; KIPLE, Kenneth F.. The Caribbean Slave: A Biological History, Cambridge, 1984; e TARDO-DINO, Franz. Le collier de Servitude: La condition sanitaire des esclaves aux Antilles françaises du XViIIè au XiXè siècle. Paris, 1985. 
R. História, São Paulo, 120, p.3-23, jan/jul, 1989.

periodicidade das demandas americanas. Apesar das navegações da África oriental contornando o Cabo da Boa Esperança serem mais dependentes das condições de tempo locais, as rotas da África ocidental respondiam às necessidades de colheita dos agricultores na América.

Se a periodicidade na movimentação de escravos era influenciada pela demanda americana, a nacionalidade, sexo e idade dos escravos incluidos no tráfico transatlântico eram, por outro lado, determinados principalmente pelas condições africanas. Todos os estudos demonstram que, excetuando-se os portugueses em Angola e Moçambique, os europeus pouco conheciam sobre as sociedades com as quais estavam lidando. Na maioria das vezes os africanos eram designados simplesmente de acordo com os portos nos quais eram embarcados e não com a língua geral, o grupo ou identidade nacional. A maioria dos traficantes não fazia idéia do que se passava a apenas alguns quilômetros da costa, e até aqueles que se estabeleciam em fortes e assentamentos fixos se restringiam a tratar essencialmente com os governos locais. Enquanto os europeus brigavam entre si de modo a proteger uma seção qualquer da costa africana ocidental, intrusos de outros grupos, tanto europeus como africanos, desviavam seus caminhos para impedir o surgimento de monopólios. Tentativas de grupos africanos no sentido de monopolização do comércio local, freqüentemente acarretavam a abertura de novas rotas comerciais por seus competidores. Alguns agricultores americanos podiam achar que os "congoleses" eram trabalhadores esforçados e outros acha-los preguiçosos, mas o que eles queriam fazia pouca diferença. Eles obtinham escravos de qualquer grupo disponível no mercado da África, Alguns portos americanos tiveram contatos mais próximos com uma dada região da África durante um bom período de tempo, dos quais o mais conhecido era o caso de Salvador na Bahia com o Golfo de Benin. Em algumas poucas ocasiões, tal como o colapso de um grande estado, ou depois de uma grande derrota militar, nações inteiras de grupos bem definidos e delineados entravam no tráfico negreiro e eram conhecidos pelos seus próprios nomes na América. Mas estes casos consistiam exceções e não regra.

O desequilíbrio numérico sexual dos africanos que partiam era determinado também pelas próprias condições africanas de suprimento mais do que pela demanda americana. Apesar de haver uma diferença de preço entre mulheres e homens na América esta era insuficiente para explicar a baixa proporção de mulheres ${ }^{20}$. As mulheres desempenhavam as mesmas tarefas

20 Para um levantamento sobre o preço de escravos por sexo na América, ver FRAGinAls, Manuel Moreno; KLEIN, Herbert S. e ENGERMAN, Stanley L. . Nineteenth Century Cuban Slave Prices in Comparative Perspective, American Historical Review, v. 88, n. 4, dez. 1983. 
KLEIN, Herbert S. Novas interpretações do tráfico de escravos no Atlântico.

manuais que os homens nas plantações da América e eram até mesmo a maioria entre os trabalhadores do açúcar, café e algodão ${ }^{21}$. Tampouco apresentavam uma maior taxa de mortalidade na travessia do Atlântico, o que poderia explicar a relutância européia em embarcá-las. A resposta parece ser simplesmente que os africanos colocavam menos mulheres à venda em seus mercados de escravos no litoral do que homens.

Havia na África grande demanda local por mulheres tanto livres quanto escravas e é esta contra-demanda que explica porque menos mulheres entravam no tráfico negreiro do Atlântico. Em algumas sociedades africanas as mulheres eram altamente valorizadas, porque eram um meio de aquisição de status, parentesco e família. Um dos traços distintivos das sociedades africanas ocidentais era a ênfase dada a sistemas matrilineares e matrilocais de parentesco. Uma vez que mesmo as mulheres escravas poderiam ser um elo significativo nas redes de parentesco, sua importância no sistema social aumentava. Além disso as mulheres escravas eram uma aquisição mais barata do que as mulheres livres locais em sociedades polígamas e, conseqüentemente eram altamente estimadas nas sociedades, que praticavam este tipo de regime matrimonial. Ainda mais importante era a difusão, na África ocidental, do uso das mulheres como principal mão-de-obra agrícola. Por todas estas razões as mulheres tinham o preço mais alto que os homens no mercado interno local africano ${ }^{22}$.

Ao lado da alta incidência de homens, o tráfico também exibia uma incidência muito baixa de crianças. Apesar das crianças não sofrerem taxas de mortalidade mais altas que qualquer outro grupo de escravos, seus preços baixos e seus custos de transporte (igual ao dos adultos) desestimulavam os traficantes a comprá-los. Parece, também, que as crianças eram mais estimadas que homens adultos no mercado escravo interno e podem não ter aparecido no litoral em grandes números devido a considerações locais de abastecimento.

21 Para a Jamaica do século XIX, ver HIGMAN, Barry W.. Slave Population and Economy in Jamaica, 1807-1834. Cambridge, 1976, p. 161-194, 197; para São Domingo do século XVIII, ver DEBIEN, Gabriel. Les esclaves aux Antilles françaises. Basse-Tcrree Fort-de-France, 1974,capítulo VIII.

22 KLEIN, Herbert S. African Women in the Atlantic Slave Trade em ROBINSON, Claire e KLEIN, Martin A., eds., Women and Slaves in África. Madison, 1983; e GALENSON, David W.. Traders, Planters and Slaves: Market Behaviour in Early English America. Cambridge, 1986, p. 105. 
R. História, São Paulo, 120, p.3-25, jan/jul. 1989.

Todos estes viéses de idade e sexo dos africanos que migraram tinham impacto direto no crescimento e declínio das populações escravas americanas. A baixa proporção de mulheres que chegavam nos navios negreiros, o fato da maioria destas mulheres serem adultas de meia idade, que já haviam passado vários de seus anos fecundos na África, e o fato de poucas crianças serem trazidas para a América foram de fundamental importância na subseqüente história do crescimento demográfico da população negra. Significava que os escravos africanos que chegavam na América não podiam se reproduzir. As mulheres que vinham à América haviam perdido um pouco de seu potencial dos anos reprodutivos, eram menos férteis e não poderiam propiciar uma geração maior do que a que chegava da África, Aquelas regiões americanas que experimentavam um pesado e constante fluxo de escravos teriam dificuldades em manter suas populações escravas, quanto menos aumentá-las, sem recorrer a mais migrantes. Entretanto, uma vez interrompida a migração africana, tomou-se possfvel o inicio de seu crescimento natural (com tanto que não houvesse emigração após a abolição).

É este constante crescimento negativo da primeira geração de escravos africanos que explica a intensidade do crescimento do tráfico negreiro americano nos séculos XVIII e XIX. À medida que a demanda de produtos americanos crescia no mercado europeu devido ao cada vez mais popular consumo de tabaco, algodão, café e acima de tudo açúcar, a necessidade de mão-de-obra aumentou e poderia ser suprida apenas com a vinda de mais africanos. Apesar de uns 2.2 milhões de escravos terem sido embarcados antes de 1700, foi apenas no início do século XVIII, que os escravos se tornaram a principal exportação da África. Foi no século XVIII e na primeira metade do XIX, que quatro quintos de todos os escravos foram transportados para América.

Mas o crescimento relativo da população americana devido ao impacto do tráfico negreiro não foi uniforme em todas as colônias ou repúblicas. Os Estados Unidos sobressaem como uma experiência um tanto singular, pois sua população escrava cresceu em taxas incomumente altas do início do século XVIII em diante. Embora a relativa marginalidade das exportações norte americanas para os mercados europeus explique o volume relativamente baixo de migração de escravos africanos e o conseqüente domínio precoce de escravos nativos na força de trabalho, a explosão demográfica resultante somente pode ser explicada por variáveis demográficas mais complexas. A taxa de crescimento de escravos nos Estados Unidos sobrepujou a 
KLEIN, Herbert S. Novas interpretações do tráfico de escravos no Atlântico.

que seria atingida no século XIX em outras sociedades escravistas que acabaram por construir uma população predominantemente mestiça ou de escravos nativos.

A hipótese inicial de certos historiadores norte-americanos afirmando o melhor "tratamento" de escravos americanos foi rejeitada por historiadores demográficos. É evidente que o período de fertilidade potencial das mulheres escravas em toda América era aproximadamente o mesmo. Uma vez que a extensão do período de fertilidade (determinado pelas idades de menarca e menopausa) está diretamente relacionada com variações nas condições de saúde, alimentação e experiência de trabalho, a falta de diferença leva à rejeição da argumentação de um melhor tratamento. Estudiosos recentes sustentavam que a principal diferença deve-se ao período de Iactação, com os escravos dos Estados Unidos adotando o esquema do norte da Europa para amamentação de um só ano, e os escravos do resto das Américas adotando práticas tradicionais africanas de amamentação por dois anos. O aspecto contraceptivo da demanda premente de amamentação por sua vez explica o maior espaçamento entre o nascimento de crianças fora dos Estados Unidos. Tal espaçamento, por sua vez, explica o maior número de crianças geradas por mulheres escravas nos Estados Unidos ${ }^{23}$.

A argumentação de um melhor tratamento não desaparece completamente, entretanto, com a questão do crescimento populacional, dada a evidência de todas as tabelas sobre a expectativa de vida dos escravos nos Estados Unidos, serem bem mais altas que a do restante da América. A média de expectativa de vida dos escravos homens no Brasil, por exemplo, ficava pouco acima dos 25 anos, e nos Estados Unidos em torno dos 35. Abstraindo a alta taxa de mortalidade infantil, a expectativa de vida daqueles que alcançavam os cinco anos de idade comparativamente era em torno dos 35 anos no Brasil e um pouco acima dos 40 anos nos Estados Unidos, Num primeiro exame isto poderia sustentar a tese do "melhor tratamento". Contudo esta mesma diferença pode ser constatada entre negros e brancos livres em todas as sociedades americanas. Isto é, brasileiros brancos viviam comparativamente menos que os brancos norte americanos. Portanto, são diferenças

23 KLEIN, Herbert S. e ENGERMAN, Stanley L.. Fertility Differentials between slaves in the United States and The British West Indies: A Note on Lactation Practices and their Implications, William \& Mary Quarterly, v. 35, n. 2,1978. 
R. História, São Paulo, 120, p.3-25, jan/jul. 1989.

gerais nas condições de saúde que explicam as diferenças de expectativa de vida e não um tratamento especial dado aos escravos.

Entretanto, não houve casos da assim chamada "média de 7 anos" de vida dos escravos americanos em qualquer sociedade escravista como pretendia a literatura contemporânea dos séculos XVIII e XIX. O mito de uma força de trabalho de vida curta estava relacionado ao declínio da população escrava, realidade esta observada sob impacto da grande imigração de escravos africanos. Os observadores não reconheciam o desequilíbrio de idade e sexo destes africanos como fator causal do crescimento negativo da força de trabalho escrava; viam, ao contrário, este declínio da população como relacionado à alta mortalidade e baixa expectativa de vida. No entanto todos estudos recentes sugerem uma taxa positiva de crescimento demográfica entre escravos nativos, e uma expectativa de vida bem acima do assim chamado sete anos de trabalho, em todas sociedades americanas ${ }^{24}$.

Esta digressão comparando taxas de crescimento e expectativas de vida demonstram extensão de ramificações das novas pesquisas sobre o tráfico de escravos. Os novos debates sobre os benefícios econômicos globais do comércio de escravos para os próprios europeus são igualmente penetrantes. Estes debates começaram com Eric Williams e continuaram nos mais atuais artigos dos diversos periódicos especializados. A discussão pode ser dividida em três questões gerais: se o tráfico de escravos foi verdadeiramente lucrativo e se estes lucros foram excessivos; qual foi o impacto do tráfico de escravos sobre o crescimento econômico da Europa; e finalmente, qual foi o impacto do tráfico e do trabalho escravo sobre o crescimento da América?

A partir do trabalho dos estudiosos de história econômica europeus, fica evidente que os lucros do tráfico de escravos não foram extraordinários pelos padrões europeus. A taxa média de $10 \%$ foi considerada boa na época mas não o era na extensão dos outros investimentos contemporâneos. Mas se os lucros não eram "astronômicos", foi um tráfico (aberto ou restrito), que gerou lucros concentrados e oligopolistas, propiciando fontes para os principais investimentos na economia européia. Sugeriu-se que os altos custos ini-

24 Ver EBLEN, Jack E., On the Natural Increase of Slave Population, 1775-1900. In Engerman e Genovese, eds.. Race and Slavery; e HIGMAN, Barry W., Slave Populations of the British Caribbean, 1807-1834. Baltimore, 1984. 
KLEIN, Herbert S. Novas ínterpretações do tráfico de escravos no Atlântico.

ciais e o tongo prazo necessário para recuperar os lucros (de até cinco anos para as viagens comuns) significava que somente firmas com muito capita) podiam lançar-se no tráfico. A maioria dos comerciantes rateavam suas despesas oferecendo ações para as viagens dos traficantes. Mas os custos de entrada, a experiência de contato e a natureza internacional das complexas negociações sugerem que haviam limites para o número de comerciantes que podiam entrar no comércio. Embora esta especialização pareça ter acontecido (e há casos de importantes empresas operando neste sentido na Inglaterra e na França), o número de comerciantes independentes que participavam do comércio e de navios equipados para o comércio em qualquer época também é impressionante ${ }^{25}$.

Este debate em tomo das porcentagens relativas de controle e participação de comerciantes gerou uma rigorosa literatura analítica ${ }^{26}$. No entanto nenhum estudioso ainda hoje conseguiu demonstrar que os ganhos do comércio fossem diretamente investidos nos primeiros empreendimentos industriais da Grã-Bretanha. Todos os estudos das fontes de capital industrial na Inglaterra apontam para origens na agricultura local e/ou comércio europeu $^{27}$. Todavia, a tese de Williams encontrou alguma sustentação quanto à questão da África ter sido um mercado para produtos manufaturados europeus, especialmente aqueles menos sofisticados. Sugeriu-se que a indústria armamentista francesa fora completamente dependente do comércio africano (servindo de pagamento para a exportação de escravos) durante épocas de paz na Europa. Pode-se demonstrar que várias outras indústrias no conti-

25 Assim, por exemplo, para movimentar 79.000 escravos per annum em 1780 (a maior cifra do comércio de todas as décadas), era necessária a utilização de 263 navios por ano.

26 Ver INIKORI, Joseph E,, Market Structure and the Profits of the British African Trade in the late 18th Century, Journal of Economic History, v. 41, 1981. Uma crítica a esta posição pode ser encontrada em dois artigos de ANDERSON, B.L, e RICHARDSON, David. Market Structure and Profits of the British African Slave trade in the late 18th Century, Journal of Economic History, v. 43, 1983 e ibid, v. 45,1985.

27 Ver ENGERMAN, Stanley L.. The Slave Trade and British Capital Formation in the Enghteenth Century: A Comment on the Williams thesis, The Business History Review, v. 46, 1972. 
R. História, São Paulo, 120, p.3-25, jan/jul. 1989.

nente e na Inglaterra também foram bastante dependentes do mercado africano. Uma vez que muitas das primeiras atividades industriais envolviam produtos mais brutos e de consumo mais popular, pode-se argumentar que o mercado africano teve um papel vital na sustentação do crescimento de algumas das mais novas e jovens indústrias da Europa ${ }^{28}$. Este comércio ainda está por ser estudado mais a fundo, mas já possibilitou uma séria avaliação do papel das exportações européias para a África neste período crucial do ínício da Revolução Industrial.

Um dos subtemas deste debate, sobre a aplicação dos lucros do tráfico de escravos foi apenas mencionado na literatura referindo-se ao papel dos lucros dos comerciantes americanos envolvidos no comércio: as índias ocidentais, os norte americanos (sobretudo os da Nova Inglaterra) e especialmente os brasileiros. Em termos de volume e capital gerado, não resta dúvida que poucas regiões se comparam às da Bahia, Rio de Janeiro e Rhode Island. $\mathrm{O}$ número de navios abastecidos para o comércio africano nestas regiões sugerem um importante argumento de capital local. Quem eram estes comerciantes e quais suas relações com a economia de plantation e os novos engenhos industriais é uma questão a ser analisada ${ }^{29}$.

O debate sobre o papel do trabalho escravo na economia americana e sobre a questão fundamental da relativa eficiência da mão-de-obra escrava africana em comparação com a mão-de-obra livre, está mais desenvolvido. Este debate tem girado em torno do livro de Robert Fogel e Stanley Engerman ${ }^{30}$, e resultou numa reconsideração do modelo de Adam Smith sobre a

28 BOULLE, Pierre. Slave Trade Commercial Organization and Industrial Growth in Eighteenth Century Nantes, Revue Française $d^{\prime}$ histoire $d$ Outre-Mer, v. 59, n. 214; e Merchandises de traite et développement industriei dans la France et L'Englaterre du XVIIe siècle, ibidem, v. 62, n. 226-7,1975.

29 O melhor estudo ató hoje é o de Coughtry, J. The Notorious Triangle. Nada comparável existe ainda para o Brasil, apesar de algumas idéias sugestivas de Luiz Felipe de Alecastro, Le commerce des vlvants: Traite desclaves et 'Pax Lusitana' dans l'Atlantique sud. (Thèse de Doctoral, Paria X, 1986),

30 FOGEL, Robert W. e ENGERMAN, Stanley L.. Time on the Cross: The Econonúes of American Negro Slavery. Boston, 1974, 2 vola. Ver também DAVID, Paul et al., Reckoning With Slavery, A Critical Study in the Quantitative History of American Negro Slavery, Nova Iorque, 1976, para algumas críticas a cata questão. 
KLEIN, Herbert S. NOVAS interpretações do tráfico de escravos no Atlântico.

suposta ineficiência do trabalho escravo. A organização dos trabalhadores cm grupos supervisionados; a extraordinariamente alta proporção entre a população economicamente ativa e a dependente (acima de $80 \%$ dos escravos eram economicamente ativos comparados aos 50 a $60 \%$ dos camponeses contemporâneos); o uso sistemático da coerção para forçar uma maior produtividade; a ausência da divisão sexual do trabalho no campo, todos estes fatores mais do que compensavam o maior incentivo dado aos trabalhadores livres assalariados. Desta forma, pode-se argumentar, que o trabalho escravo não era um desvio da já escassa fonte de capital americana, mas antes o melhor investimento possível no período pré-industrial do desenvolvimento agrícola.

A última importante preocupação dos estudos mais recentes sobre o tráfico de escravos focaliza as causas e conseqüências de sua abolição. Já é bem conhecido o fato da campanha para a abolição do tráfico de escravos no Atlântico, que começou no ultimo quartel do século XVIII, ser considerada o primeiro movimento político de massa baseado em propaganda política moderna, da história da Inglaterra, senão de toda Europa. A literatura tradicional via esta campanha como uma cruzada moral realizada às custas dos lucros do tráfico ${ }^{31}$. Uma vez abolido o tráfico nas colônias inglesas em 1808 , os britânicos tentaram influenciar todos os principais países escravistas europeus a desistir do tráfico. Esta campanha, por sua vez, custou muito em termos do comércio perdido, do afastamento de aliados tradicionais e dos altíssimos custos do bloqueio naval ${ }^{32}$.

Apesar de estadistas e escritores ingleses terem retratado a campanha deles como sendo sempre uma questão moral, já existia considerável literatura contemporânea atacando seus motivos. Cubanos, espanhóis e brasileiros,

31 Os trabalhos tradicionais incluem KLINGBERG, F.J.. The Anti-Slavery Movement in England. New Haven, 1926; e COUPLAND, R., The British Anti-Slavery Movement. Londres, 1933.

32 LE VEEN, L. Phillip. British Slave Trade Suppression Policies, (1821-1865). Nova Iorque, 1977 examina os custos econômicos deste esforço. Para uma análise recente e detalhada das manobras complexas dos governos brasileiros e espanhois para defenderem seu tráfico ver, MURRAY, David R.. Odious Commerce, Britain, Spain and the Abolition of Cuban Slave Trade. Cambridge, 1980; CARRION, Arturo Morales. Auge y decadencia de la trata negrera en Puerto Rico (1820-1860). Rio Pedras, 1978; BETHEL, Leslie. The Abolition of Brazilian Skive Trade, Cambridge, 1970. 
R. História, São Paulo, 120, p.3-25, Jan/jul, 1989.

objetos da maioria dos ataques dos abolicionistas ingleses após 1808, argumentavam que a campanha era motivada por temor de competição, especialmente depois de 1834, quando a safra do açúcar passou a se dar com mãode-obra livre nas ìndias ocidentais inglesas. Os latinos argumentaram que o motivo da campanha anti-escravista era o de afastar os produtos, eficientemente produzidos por escravos, do mercado europeu forçando o aumento das despesas com mão-de-obra. Mais tarde este argumento também foi utilizado por estudiosos da história econômica das İndias ocidentais, afirmando que o sistema de plantation pós-extinção do tráfico era ineficiente e apresentava sérios problemas econômicos. ${ }^{33}$ Eric Williams e outros foram mais longe sustentando que motivações econômicas explicavam o êxito da campanha abolicionista inglesa contra os demais traficantes de escravos, uma vez que as plantações das índias ocidentais inglesas não podiam competir com as francesas, espanholas e brasileiras.

Contrariamente a este modelo econômico causal, estudiosos recentes afirmam que em fins do século XVIII e início do XIX a economia das índias ocidentais inglesas era próspera. Mesmo depois da abolição do tráfico, as ilhas mais antigas assim como as mais novas eram competitivas no mercado europeu e somente a abolição da escravidão propriamente dita abalou a economia local, Apesar da campanha abolicionista não mais ser vista simplesmente como uma cruzada moral por qualquer grupo de estudiosos de importância, a argumentação determinista econômica de Williams e seus correligionários ainda está aberta ao debate ${ }^{34}$.

Como já ficou evidente, as questões referentes ao tráfico desencadearam debates mais complexos, muitos dos quais estão longe de qualquer resolução. Outras áreas que poderiam desenvolver-se a partir destas novas pesquisas estão por ser exploradas. Assim, o vigoroso debate sobre as origens culturais afro-americanas, já bem discutidas do ponto de vista americano ainda devem integrar-se às novas descobertas do estudo do tráfico. A

33 RAGATZ, L. J.. The Fall of the Planter Class in the British Caribbean, 1763-1833. Nova Iorque, 1928.

34 Ver ANSTEY, The Atlantic Slave Trade and British Abolition; os dois trabalhos de DRESCHER, Seyrnor. Econocide: British Slavery in the Era of Abolition. Pittsburgh, 1977; e Capitalism and Anti-Slavery. Nova Iorque, 1986; e DAVIS, David B, Slavery and Human Progress. Nova Iorque, 1984, e mais recentemente os ensaios em SOLOW \& ENGERMAN, eds..British Capitalism and Caribbean Slavery. 
KLEIN, Herbert S. Novas interpretações do tráfico de escravos no Atlântico.

partir do trabalho de Debien e outros estudiosos franceses, bem como das cuidadosas reconstruções de Curtin, Lovejoy e outros, já temos uma idéia clara e razoável quanto aos grupos que participaram do tráfico e aos que se estabeleceram nas diversas regiões da América. Mas ainda não se tentou nada com a qualidade da síntese sugerida primeiramente por Herskovits, apesar de algumas recentes pesquisas brasileiras terem começado a elaborar novas abordagens da transferência cultural ${ }^{35}$.

Também deve-se salientar que muitas das questões que apresenta estão longe de serem resolvidas nesta ou naquela direção. Uma vigorosa empreitada desenvolveu-se criticando as cifras obtidas por Curtin ${ }^{36}$. Da mesma forma, muitas novas pesquisas estão surgindo sobre as questões de saúde e transmissão de doenças. O debate sobre as causas da mortalidade no tráfico continuam ${ }^{37}$, e finalmente, permanece o longo debate quanto ao impacto do tráfico de escravos sobre a África ${ }^{38}$. Simulações de declínio demográfico no computador, modelos de estabelecimentos regionais e aldeias abandonadas, reestimativas do total da população e das taxas de crescimento a longo prazo criaram um novo campo de estudos demográficos pré-coloniais africanos ${ }^{39}$.

35 HERSKOVITS, Melville J.. The Myth of the Negro Past, Nova Iorque, 1941. As novas pesquisas brasileiras podem ser encontradas em VERGER, Pierre, Flux e( reflux, e mais recentemente em CUNHA, Manuela C. da. Negros, estrangeiras. Os escravos libertos e sua volta a África. São Paulo, 1985,

36 Grande parte desta nova literatura está resumida em LOVEJOY, Paul E,, The Volume of the Atlantic Slave Trade: A Synthesis, Journal of African History, v. 22, n. 4, 1982; e em ELTIS, David. The Nineteenth Century Trans-Atlantic Slave Trade: An Annual Time Series of Imports into the Americas broken down by Region, Hispanic American Historical Review, v. 67, n. 1,1987.

37 Ao lado dos trabalhos supracitados, um levantamento recente pode ser encontrado em COHN, Raymond L. e JANSEN, Richard A.. The Determinants of Slave Mortality Rates on the Middle Passage, Explorations in Economic History, v. 19, 1982.

38 Um conjunto de trabalhos proveitosos sobre este assunto, de Inikori, Patrick Manning e John Thorton pode ser encontrado em FYRE, Christopher e MCMASTER,David, eds.. African Historical Demography. Edinburgo, 1981.

39 Ver, por ex. o interassante trabalho de MANNING, Patrick. The Enslavement of Africans: A Demographic Model, Canadian Journal of African Studies, v. 15, 1981; e The Impact of Slave Exports on the Population of the Western Coast of Africa, 1700-1850. Trabalho apresentado no Colóquio internacional sobre Tráfico de Escravos, Nantes, julho de 1985. 
R. Hitória, São Paulo, 120. p.3-25, jan/jul. 1989.

Qualquer que seja o estado atual do debate ou da resolução de uma dada questão em particular, é evidente que a natureza da nossa compreensão da escala, importância e impacto do tráfico de escravos do Atlântico, foi profundamente modificada pelo enorme esforço de pesquisa realizado nos últimos vinte e cinco anos. ${ }^{40}$

ABSTRACT: The surge of systematic research on the slave trade changed significant ideological and statistical errors dating from the abolitionist struggle. Concentrating on local a frican conditions, theses studies confirmed a majority of male slaves as opposed to one third of women and $10 \%$ of children. They established other significant peculiarities concerning demographic data or the relative percentages of participation of the different European nationalities. The intensification of research efforts resulted in significant re-evaluations on topics such as the role the slave trade played in the economic growth of european countries, the abolitionist campaign bringing new data on the distribution of the different african cultures in the new world or on the demographic and economic consequences that the slave trade brought to the african countries.

UNITERMS: Slave Trade, slavery, abolitionism, historiography.

40 Apesar de ainda não ter aparecido um estudo definitivo abarcando todos estes assuntos, levantamentos recentes sobre o tráfico finalmente começaram a incorporar muitas destas novas pesquisas. Ver DESCHAMPS, Hubert. Histoire de Ia traite des noirs. Paris, 1971; PLUCHAN, Pierre. La Route des esclaves, négriers et bois d'ébène au XVIII e siècle. Paris, 1981; RAWLEY, James A.. The Trans-Atlantic Slave Trade. Nova Iorque, 1981; e RENAULT, François e DAGET, Serge. Les Traites négrières en Afrique. Paris, 1985. 